OPEN ACCESS

International Journal of Management \& Entrepreneurship Research

P-ISSN: 2664-3588, E-ISSN:2664-3596

Volume 2, Issue 4, P.No. 231-243, August, 2020

Fair East Publishers

Journal Homepage: www.fepbl.com/index.php/ijmer

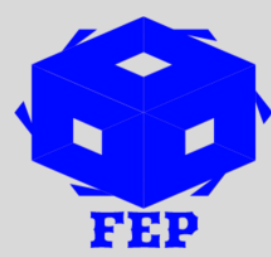

\title{
EXAMINING SOCIAL CLASS DIFFERENCES IN ALCOHOL CONSUMPTION AND HOUSEHOLD CONFLICTS: A QUANTITATIVE APPROACH ON CHRISTIAN CONSUMERS IN BURKINA FASO
}

\author{
Dr. Théophile Bindeouè Nassè ${ }^{1,2,3}$ \\ ${ }^{1}$ University for Development, Wa Campus. \\ ${ }^{2}$ Polytechnic College of Youth (Burkina Faso). \\ ${ }^{3}$ Saint Thomas D'Aquin University (Burkina Faso).
}

*Corresponding Author: Dr. Théophile Bindeouè Nassè
Corresponding Author Email: nassetheophile2009@gmail.com

Article Received: 17-07-20

Accepted: $18-08-20$

Published: 05-09-20

Licensing Details: Author retains the right of this article. The article is distributed under the terms of the Creative Commons Attribution-NonCommercial 4.0 License (http://www.creativecommons.org/licences/bync/4.0/) which permits non-commercial use, reproduction and distribution of the work without further permission provided the original work is attributed as specified on the Journal open access page.

\begin{abstract}
The present research purposes are to explore the relationships of social class and alcohol consumption, and the relationships of alcohol consumption and household conflicts in Ouagadougou. A quantitative research design is used to collect data from both primary and secondary sources for analysis using sphinx IQ software. Some self-administered questionnaires were used for data collection. The quantitative results demonstrate that social class is a moderator of alcohol consumption and conflicts. The recommendation is that very poor, poor and middle-class consumers should strongly moderate their alcohol consumption, because they are those who are more affected by the negative effects of alcohol intake.
\end{abstract}

Keywords: Social Class, Alcohol Consumption, Household Conflicts, Ouagadougou.

\section{INTRODUCTION}

Alcohol consumption is a long-standing practice in human society. Alcohol is used as a beverage in normal daily activities across the world (Bazié, 2011; Nasse, 2018). It is also used in some religious activities as well as social functions (Dumbili, 2013; Porter, 2013; Nasse et al., 2019) In fact the alcohol industry has become one of the largest sectors of production in the world. However, research has shown that alcohol consumption has diverse effects on consumers, including conflicts. Research on alcohol consumption and conflicts has been done in many parts of the world including Africa (Valentine et al., 2010; Amankwaa et al., 2012; Dery \& Diedong, 2014; 15; Nasse et al. 2016). Burkina Faso is the third most alcohol consumer 
country in the West Africa region, after Nigeria and Ivory Coast (Ritchie \& Roser, 2020). This is an indication that alcohol plays a very important role in people's lives in Burkina Faso. Much of the literature on the effects of alcohol is dedicated to other effects of the substance. However, there is an emerging literature that confirms some relationships between alcohol consumption and violent conflicts in intimate relationships (Murphy et al., 2005, Dery \& Diedong 2014). There is not much work done in Burkina Faso to establish the relationship between alcohol consumption and household conflicts. In the same vein, no work has concurrently shown the effect of social class on one's level of alcohol consumption. This study is to fill this research gap by exploring how social class moderates individual's alcohol consumption levels and also how alcohol consumption relates to household conflicts using Ouagadougou, in Burkina Faso as the setting.

\section{Theoretical Underpinning}

Social class theory: Social class theorists perceive society as a stratified system of interrelationships that define individuals, their rights, and responsibilities in relation to the position they occupy in the social stratum of that society. Consequently, questions of rights and freedom of choices are determined by the privileges imposed by one's social class (Marx, 1886; Shapiro, 1960). In reality, the institution of the private property state with the emergence of entrepreneurial capitalism and free market systems has led to a natural imposition of economic class realism that regulates individual taste, purchasing power, purchasing decisions and choices. Rational choice theory requires a vertical relationship between one's social class and the quality and quantity of goods the individual purchases and consumes. An aspect of this study is to establish if the social class of an alcohol consumer has a moderating effect on the quantity of alcohol s/he consumes.

The economic theory of consumption: These theorists arguments state that consumers purachase decisions, and consumption decisions rely on some economic criteria (Ouédraogo, 2007), Kitchathorn (2009), Nasse (2019). Thus, some economic criteria such as the purchasing power, the consumer income also take into consideration that some emotional factors may affect consumption.

\section{The Research Concepts}

The research aims to define the concepts that are in line with the topic.

Conflict: The concept of conflict has been well-defined by some researchers in several contexts. Etymologically, the concept of conflict is originated from the Latin word 'conflictus' which means an opposition between some entities that have different feelings (Sicard \& Rognon, 2015). In the western context, Ross (1993) shares the same view as some authors like Deutsch (1973) and, Pruitt and Rubbin (1986) by defining conflicts as behaviors that are discordant or as perceptions that are contradictory. Ross (1993) illustrates it by these words: "Conflict is variously defined in terms of incompatible behaviors or divergent perceptions" 'Ross (1993, p. 74). This approach to the concept of conflict is narrow and it fails to bring out its aggressiveness' part. Still in the Western context, conflict is approached by Gulliver (1979) and Ross (1993) as a process of communication in the society that bears a clear cultural meaning, by protagonists that share the same contextual realities. Goodhand and Hume (2009) have defined conflict as a disagreement resulting from individuals or groups that differ in behavior, beliefs, and values or in needs. The concept of conflict as approached by Goodhand and Hume is limited by the fact 
that it does not involve the violent aspect of conflict, but it rather shows conflict to be a mere disagreement. In the African context, the concept of conflict has been approached differently by numerous authors. First of all, in Burkina Faso, the concept of conflict has been defined in a religious environment by Nasse et al., (2016) as a misunderstanding between individuals and groups as a response to a given misbehavior that affect a given religious community or group. The concept of conflict as approached by Nasse et al., depicts the social violence aspect of conflict and that is why recommendations have drawn the attention of political authorities and managers to help prevent these conflicts. Second, in Ghana, the concept of conflict has been defined by different authors. For Sulemana (2009) the concept of conflict refers to a disagreement or an antagonism between individuals or different groups of people that is associated with violence. For Awedoba (2009) and for Awedoba (2011) conflict is viewed as a relationship between two or more parties centered on differences, disagreement and some issues of common interest or concern, divergence, incompatibilities. For Awedoba conflicts exist because of the contact between human being in term of politics, culture, and economic concerns. Mahama and Longi (2013) show that conflict is an unavoidable phenomenon that bears disagreements or differences which can result into aggressive clashes. Dery and Diedong (2014) relatively understand conflicts as a domestic violence that involves both adult men and women who are victims of physical, mental, emotional and sexual aggression. For Marfo et al., (2018) the concept of conflicts is approached as a disagreement between interreligious individuals, communities or groups centered on needs such as space and different views about the wearing of religious veil. Sabogu, Nasse and Osumanu (2020), conflict is a form of difference and violence over some selfish interests, or individual greediness, and characterized by aggressive actions or violence. For further, in the Middle East context, Al-Hyari, et al. (2012) has demonstrated that the consumer behavior in Saudi Arabia, has a link with religiosity, and that the sales of insane products generates conflicts. These conflicts are sometimes expressed in a form of social violence against the manufacturers or the sellers of the non-desired products. Conflicts are observable under in a form of products boycotting or products rejection by consumers. Moreover, in the Asian context, particularly in India, Poulose and Srinivasa (2009) have demonstrated that conflict refers to a high-risk behavior that involves two or more individuals that is associated with violence or aggressive behavior. For Poulose and Srinivaa, these conflicts involve violent sexual behavior and violent criminal acts and sometimes some injurious expressions or terms. However, in this research the definition of the concept of conflict is understood to be a disagreement, an antagonism, a difference between two or more parties that involves aggressiveness, or violence. Thus, the type of conflicts that are concerned here is household conflicts (or domestic conflicts), religious conflicts, and street conflicts, gender conflicts, the inter-religious aspects of conflicts, the intra-religious aspects of conflicts, the intra-personal conflict aspects of conflicts and the interpersonal aspects of conflicts.

Alcohol consumption: The concept of alcohol can be defined in several ways. The concept of alcohol is defined by the French dictionary Larousse as a drink or a juice that has undergone a process of fermentation. However, the concept can also be understood to be any type of drink that contains alcohol. For some authors like, Amankwaa, Reed and Owens (2012), Nasse et al. (2016) alcohol refers to the industrial fermented drinks that are sold or consumed. However, in this study the concept of alcohol refers to any drink that has been fermented either through some traditional ways of production or through some modern or industrial ways of production. Thus, 
the type of alcohol that is concerned by this research is the ethanol $\left(\mathrm{C}_{2} \mathrm{H}_{5}-\mathrm{OH}\right)$, which is drinkable. In the context of Burkina Faso, one can distinguish two types of alcohol: the traditional alcohol and the modern or industrial alcohol.

Social class: According to Karl Marx, the concept of social class has two dimensions: the proletarian class and the rich class. For Marx (1886), the social class is composed of the proletarian class (the people who are poor) that are exploited by the rich class through the means of labor, or retribution in terms of the work done.

- Data analysis: In this research, the qualitative data is transcribed by hand using an audio software. Then, the qualitative data is processed using the qualitative version of Sphinx IQ. A content analysis of the qualitative data is made. The quantitative data is also processed thanks to the quantitative version of Sphinx IQ.

- Ethical implications: In this research, there are some ethical measures to be taken into account as what is normal to be considered for a scientific research (Creswell, 2009). In this research in order to increase participation, respondents are not requested to give their names, and information given by the respondents is kept confidential (Nasse, 2018).

Research hypotheses or propositions and research model.

$\mathrm{H}_{1}$ : There is a relationship between alcohol consumption and conflicts

$\mathrm{H}_{0}$ : There is not a relationship between alcohol consumption and conflicts

$\mathrm{H}_{2}$ : Social class is a moderator of the relationship between alcohol consumption and household conflicts.

$\mathrm{H}_{0}$ : Social class is not a moderator of the relationship between alcohol consumption and household conflicts.

\section{MATERIALS AND METHOD}

For the quantitative research a secondary data is used. The secondary data is from the previous research paper of Nasse (2019) on alcohol consumption and conflicts. Quantitative research allows the quantification of the data that is obtained through a questionnaire that is administered to the different respondents, in order to bring out some correlations (Van Campenhoudt \& Charlier, 2014), exploratory factor analysis, graph of correlations and regression analysis. In this research, this is done taking into strict consideration the research hypotheses, independent and dependent variables, and the general and specific objectives of the research. The following sections explain in detail the research hypotheses and the quantitative research procedure including the sample population, frame, size as well as unit of analysis. It also presents the data collection mechanisms, procedures and tools as well as the research setting, the data analysis, the reliability of the research, the ethical implications of the research, the scope of the research, and the research limitations.

\section{Research Procedure}

The research process is divided into several steps.

Sampling Technique: The techniques of random sampling, and snowball sampling procedures are combined to make the selection of respondents by making sure that each respondent is independently taken from the targeted research population (Anderson, Sweeney, Williams, Camm, \& Cochran, 2015). The approach and sampling procedure are explained in detail under sample population, sample frame, sample size and unit of analysis below. 
Sample Population and Sample Frame: The research determined the sample size from a larger nationwide Christian population statistics of Burkina Faso. The total number of Christians in Burkina Faso is used, and data from secondary sources indicating the estimated number of Christian alcohol consumers (Nasse, 2018) adopted to calculate for the city of Ouagadougou. This will then constitute the sample frame from which the sample size is calculated using Ganassali (2009) and Hejase \& Hejase (2013) sample size determination formula. According to the national statistics, the total population of Burkina Faso in 2010 is 14, 017, 262 inhabitants. Christians represent $23.2 \%$ of the total population which represents 3,249,390 Christians (INSD, 2010). The study area, Ouagadougou has a total population of $1,915,102$ inhabitants. Applying the $23.2 \%$ of national percentage of Christians to the total population of Ouagadougou, it is estimated that 444,304 Christians live in Ouagadougou. According to (Nasse, 2018), one out of every twelve Christians in Ouagadougou is an alcohol consumer, this constitutes $8.33 \%$. The final sampling frame is: $(8.33 / 100) \mathrm{X} 444,304$ giving 37,011 Christians. This constituted the sample frame from which the sample size is calculated. Sample Size and Unit of Analysis: From the above sample frame of 37,011 the researcher applied the Ganassali (2009) the Hejase and Hejase (2013) sample size determination formula to derive the sample size for the research. The procedure is as follows: $n=(p)(1-p) /(e / Z)^{2}$, where, $\mathrm{p}$ represents the selected proportion of an attribute, for example gender. Here, assuming $50-50$ female to male ratio, $\mathrm{p}=0.50$ or $50 \%$; e represents the level of precision or accuracy set for this research, here $6.5 \%$, and $\mathrm{Z}$ is the number related to degree of confidence in this case $Z=1.96$ or $95 \%$ confidence (Ganassali, 2009; Hejase \& Hejase, 2013). In this case the operation becomes: $\mathrm{n}=(0.5 \times(1-0.5)) /(\mathrm{e} / 1.96)^{2}=0.25 /(\mathrm{e} / 1.96)^{2}$. The number of people to interview for a maximum error of $6.5 \%$, then is $n=0.25 /(0.065 / 1.96)^{2}=229$ people.

From the above formula a sample size of 229 Christian alcohol consumers from the sample frame of 37,011 is therefore enough at an error margin of 6.5.

Data Collection Mechanism, Procedures and Tools: The primary tool used for the quantitative data collection is a questionnaire. It was designed with strict reference to the objectives of the research. Whilst the sample size as indicated above is 229 the researcher sent out 280 questionnaires. This is to ensure that even if some questionnaire were not returned by some respondents, the final sample should not go much below the target sample size of 229 . The city was clustered into four zones, thus the Northern part, the Southern part, the Eastern part and the Western part. Each cluster is allocated a quota of 70 respondents to fill the questionnaires. Respondents were selected through random sampling (where respondents were given the same chance to be selected combined with snowballing technique. In this, potential respondents were approached in drinking bars, restaurants, wedding and naming ceremonies and other celebrations where observations show that they consume alcohol. Questions were asked to ensure the respondent satisfies all the established criteria for the unit of analysis before they were given a questionnaire to complete. The criteria of selection included being a Christian living in Ouagadougou, attending Church service and participating in church activities, drinking alcohol and found within the geographical zone where the questionnaire was being distributed. The questionnaire is designed in French language. Most of them were self-administered by the respondents after the researcher explained the context and content to them. This category of respondents was those who are literate enough to read and understand the content of the questionnaire and could answer properly by themselves. Some few questionnaires were 
researcher administered to the respondents who could not read and write in French. In the case of the latter, the local languages were used to conduct the research. Whilst some respondents filled their questionnaires on the spot, others preferred to take the questionnaire home and to fill it before returning it at their free time. Their contact details were taken by the researcher to enable follow up for the questionnaire. Out of the total number of 280 questionnaires sent out, 248 were returned. Out of this, 241 questionnaires were fully completed and considered for analysis in the research. Seven questionnaires were either not properly filled or were incomplete, and were removed from the lot. The 241 respondents retained surpasses the 229 target sample size, but for the fact that the retained number of respondents did not go below the expected, it is considered acceptable and even more representative. The completion rate of the quantitative study is as follows:

Completion rate $=($ Number of complete questionnaires received $/$ Number of total number of questionnaires received) X 100 .

Completion rate for the quantitative study $=(241 / 248) 100=97.17 \%$. The completion rate is acceptable and it shows that respondents were motivated to participate in the study.

Research Instruments: This section is focused on the description of the questionnaire. It shows the number of questions, the focus of the questions, where the questions are from. The research is carried out through the use of a quantitative questionnaire. The first questionnaire is addressed to the consumer of alcoholic drinks. The number of questions is fifteen. These questions are constructed using the different variables identified through the literature review and the results of the previous qualitative research. The items of the variables are measured on a Likert scale in four items ranging from "Strongly disagree" to "Strongly agree." These four items are respectively "Strongly disagree", "Disagree "," Agree, "Strongly agree". The Likert scale in four items is selected not only to avoid neutral answers and to collect the answers of a good quality but also to allow respondents to save time as most of them were in hurry. A scale to more than four items could embarrass the respondents who felt they did not have enough time to answer the questions. The specified view of Ganassali (2009) seems significant: "With four items the respondent is requested to match the effort to tick one side or the other of the central position, which is sometimes chosen as a safe haven"'. Furthermore, to better quantify the data discussed, a number is assigned to each data response. Thus, the answer "Strongly disagree" is the number 1, the answer, "Disagree" is the number 2, the answer, "Agree" is the number 3, and the answer "Strongly agree" is the number 4.

Research Setting: The country where the quantitative research is conducted is Burkina Faso where participants are identified. The city of Ouagadougou is composed of several ethnic groups and several Christian religious groups that are classified into two main groups: the evangelical Christians and the Roman Catholic Christians. The research field includes the main city that is Ouagadougou, for a period of 10 months.

Research Participants: The research participants for the quantitative research should also be some experienced consumers of alcohol who are living in the capital city of Burkina Faso. They should also have experienced conflictual situations related to the consumption of alcohol in their living environment. Consequently, the participants are the consumers that are able to understand the research topic in order to give their personal view other orally or in a written basis. 
Data Analysis: The quantitative data is analyzed using the quantitative version of sphinx IQ software. This software helps in computing the data and mining it to bring out descriptive statistics, the alpha Cronbach of the items to be measured, as well as correlations between different variables, and the graphs that shows the relations between the variable. The chosen research instruments must allow people to better appreciate the phenomenon to measure and to see if it is well measured (Carricano, Poujol, \& Bertrandias, 2010). Both research instruments are already validated by some lecturers. Post data validation is made and the respondents reiterate the same points of views.

Reliability of the Research: The results are tested several times to see if the same results are got or if participants reiterate the same views. For this reason, the data is collected and analyzed several times. The subsequent section presents the ethical implications.

Ethical implications: In this research, there are some ethical measures to be taken into account as what is normal to be considered for a scientific research (Creswell, 2009; Quivy, Van Campenhoudt, 2011). To increase participation, respondents are requested to give their names also quantitative information given by the respondents are kept confidential, to protect their identity. The sociopolitical context marked by some political crisis, the rise of insecurity and the limitation of the freedom of speech has brought respondents to be careful and cautious towards interviewers (Nasse, 2018; Lankoandé \& Ouédraogo, 2016).

\section{RESULTS}

The descriptive statistics of the quantitative data show that the total number of Christians in this research represents 241 respondents what is a sample of $100 \%$ of Christians. For further, alcohol consumers are from different religious affiliation. 8.3\% of the respondents are Assembly of God Christians, $5.8 \%$ of the respondents are Apostolic Christians, $13.7 \%$ of the respondents are Baptist Christians, $0.8 \%$ of the respondents are Centre International d'Evangelisation Christians, $2.9 \%$ of the respondents are Mennonite Christians, $13.3 \%$ of the respondents are Presbyterian Christians, 52.3\% of the respondents are Roman Catholics. The high rate of the Roman Catholic consumers could be explained by the fact that in the socio-cultural context of Burkina Faso, not only Roman Catholics are more numerous in term of national statistics, but also Roman Catholic Christians are tolerant in regard of alcohol consumption (Nasse, 2018). The Roman Catholics consumption culture requires that Christians drink alcohol moderately. The limited number of Evangelicals can be explained by their small number in term of national statistics, and by the fact that evangelical Christians are not tolerant towards alcohol consumption (Nasse, 2018) as their doctrines condemns alcohol consumption. Nevertheless, some Evangelicals also tend to be a little bit tolerant in regard of alcohol consumption. Furthermore, talking about the respondents' age, $20.25 \%$ of the respondents have their age between 18 and 25 years; $37 \%$ of the respondents have their age between 26 and 35 years; $30.25 \%$ of the respondents have their age between 36 and 45 years; $12.5 \%$ of the respondents have their age between 46 years and above. The respondents from 26 years old to 35 years old are more numerous because first the population in majority is young and second it is at this range of age that the Burkinabe youth tend to follow the drinking fashion as some are working and can afford the purchase of drinks for consumption. Besides, about the respondents' gender, $16.2 \%$ of them are women and $83.8 \%$ of them are men. The low rate of women could be explained by the fact that Christian female consumers are sometimes more stigmatized when they drink alcohol as compared to Christian male consumers. Furthermore, about the 
respondents' marital status, $54.4 \%$ are single, $2.9 \%$ are engaged, $40.2 \%$ are married and $2.5 \%$ are divorced. Likewise, as regards to the respondents' profession, 17.5\% are public employees, $51.7 \%$ are private employee, and $30.8 \%$ are unemployed. To add, on the subject of the respondents' social class, $1.5 \%$ are very poor, $52.5 \%$ are poor, $37.5 \%$ are rich, and $08.5 \%$ are very rich.

\section{Alcohol Consumption and Household Conflicts}

For the analysis of the quantitative data, the items of the different items of the variable are measured to see their consistency. The alpha Cronbach is used to measure the different items consistency. The alpha of Cronbach helps to find out if the items are strongly homogeneous between them. The Principal Component Analysis (PCA) shows that the items related to the alcohol consumption variable are not independent but that they are strongly correlated between them. The alpha of Cronbach value is 0.77 and it indicates that the items are strongly correlated between them. The Principal Component Analysis (PCA) reveals that there are three main factors F1, F2, F3, that explain $91.73 \%$ of the total variance. The results are summarized in the following Table 2.

\section{Table 2}

\begin{tabular}{|c|c|c|c|c|}
\hline & Item 1 & Item 2 & Item 3 & Item 4 \\
\hline Item 1 & - & 0.36 & 0.64 & 0.37 \\
\hline Item 2 & 0.36 & - & 0.37 & 0.63 \\
\hline Item 3 & 0.64 & .0 .37 & - & 0.38 \\
\hline Item 4 & 0.37 & 0.63 & 0.38 & - \\
\hline
\end{tabular}

The Principal Component Analysis (PCA) shows that the items related to "Household conflicts" variable are not independent but that they are strongly correlated between them. The alpha of Cronbach value is 0.82 and it indicates that the items are strongly correlated between them. The Principal Component Analysis (PCA) reveals that there are three main factors F1, F2, F3, that explain $93.79 \%$ of the total variance. The results are summarized on the following Table 3.

Table 3

Alpha of Cronbach of the Variable Household Conflicts

\begin{tabular}{lllll}
\hline & Item 9 & Item 10 & Item 11 & Item 12 \\
\hline Item 9 & - & 0.35 & 0.49 & 0.48 \\
\hline Item 10 & 0.35 & - & 0.57 & 0.55 \\
\hline Item 11 & 0.49 & 0.57 & - & 0.72 \\
\hline Item 12 & 0.48 & 0.55 & 0.72 & - \\
\hline
\end{tabular}

(Source: Fieldwork, 2019)

Table 4

Relationships between 'Alcohol Consumption' and 'Household Conflicts'

\begin{tabular}{llc}
\hline Variables & Results & Relationship \\
\hline "Alcohol consumption" and "Household conflicts" & $\mathrm{p}=0.009 ;$ dof $=15 ; \chi^{2}=31.00$ & Very significant \\
\hline "Household conflicts " and "Alcohol consumption" & $\mathrm{p}=0.009 ;$ dof $=15 ; \chi^{2}=31.00$ & Very significant \\
\hline${ }^{*} \mathrm{p}<0.05$ & & \\
\hline
\end{tabular}

(Source: Fieldwork, 2019)

$\mathrm{H}_{1}$ : There is a relationship between alcohol consumption and household conflicts

$\mathrm{H}_{0}$ : There is not a relationship between alcohol consumption and household conflicts 
Table 4 indicates that the crossing of "alcohol consumption" and "household conflicts" is very significant because the $\mathrm{p}=<0.009$ value; the degree of freedom value $=15$; and the chi-square value $\chi^{2}=31.00$ are very significant (see Table 4 ). The reverse effect is correspondingly very significant. The conclusion is that the null hypothesis is rejected and the alternative hypothesis 1 is accepted. There is a relationship between "alcohol consumption" and "household conflicts"

\section{Social, class, Alcohol consumption and household conflicts}

Table 5

Relationships between 'Social Class', 'Alcohol Consumption' and 'Household Conflicts'

\begin{tabular}{lll}
\hline Variables & Results & Relationship \\
\hline "Alcohol consumption" and "Social class" & $\mathrm{p}=<0.01 ;$ dof $=45 ; \chi^{2}=147.58$ & Very significant \\
\hline "Household conflicts" and "Social class" & $\mathrm{p}=<0.01 ;$ dof $=45 ; \chi^{2}=110.43$ & Very significant \\
\hline "Household conflicts" and "Alcohol consumption" & $\mathrm{p}=0.009 ;$ dof $=15 ; \chi^{2}=31.00$ & Very significant \\
\hline${ }^{*} \mathrm{p}<0.05$ & & \\
\hline
\end{tabular}

(Source: fieldwork, 2019)

$\mathrm{H}_{2}$ : Social class is a moderator of the relationship between alcohol consumption and household conflicts.

$\mathrm{H}_{0}$ : Social class is not a moderator of the relationship between alcohol consumption and household conflicts.

Table 5 indicates that the different variable crossing are very significant. The crossing of alcohol consumption and social class is very significant because the $p$-value $p=<0.01$, the degree of freedom dof $=45$, and the chi-square value $\chi^{2}=147.58$ are significant. The crossing household conflict and the social class is found very significant because the $p$-value $p=<0.01$, the degree of freedom value $\mathrm{dof}=45$, and the Chi-square value $\chi^{2}=110.43$ are very significant. In addition the crossing of "alcohol consumption" and "household conflicts" is very significant because the $\mathrm{p}$-value $\mathrm{p}=<0.009$, the degree of freedom value $=15$, and the chi-square value $\chi^{2}=31.00$ are very significant. The reverse effect is correspondingly very significant. The conclusion is that the null hypothesis is rejected and the alternative hypothesis 2 is accepted. There is a relationship between "social class", "alcohol consumption" and "household conflicts"

\section{DISCUSSION OF THE RESULTS}

\section{Alcohol Consumption and Household Conflicts}

The present research shows that alcohol consumption is associated with household conflicts as some previous studies on the same subject have shown the same results (Dery \& Diedong, 2014; Nasse, 2020). However, the present study aim to show that another important variable namely the social class has a moderating influence on the relationship between alcohol consumption household conflictual situations.

\section{Social, Class, Alcohol Consumption and Household Conflicts}

Some studies show that alcohol consumption is a source of household conflicts (Dery \& Diedong, 2014; Nasse, 2020) and some other studies show that alcohol consumption is a moderator of the relationship between alcohol consumption and household conflicts (Nasse, 2020). The present study has shown that the social class has an influence on alcohol consumption and household conflictual situations. The observations in the present research have shown that poor consumers and middle-class consumers are those who consume more alcohol than the other classes. This could be explained by the fact that the very poor class, the 
poor class and the middle class, have more socio-economic problems (poverty, unemployment, poor income, limited education level, ) more consideration for traditional consumption culture conservation. Nevertheless, the household conflictual situations related to alcohol consumption are found at all the social class levels.

\section{CONCLUSION AND IMPLICATIONS}

It has been shown that alcohol consumption is at the base of household conflicts. In term of limitations, there are some challenges which are linked to the concept of conflicts and alcohol consumption. These concepts have been used in previous researches by some eminent authors that have defined them in their own context. Hence, the present research has addressed these challenges by redefining these concepts, and this is subject to some bias in the research. There are also some challenges that are linked to the methodology that has been used here. It is sure that some of the challenges on the research ground may have affected some aspects of the data collection. This situation, then may have affected the final results. Finally, it would be helpful not only to extend this research to other different research areas different from the industrial drinks sector, or to extend it to other context of West Africa, or to conduct it in other African countries to see whether the results are the same or not. First, in regard of key findings the recommendation is that alcohol consumption and conflictual household situations should be taken into account by researchers to enrich scientific knowledge through further investigations in other contexts. Secondly, conceptual findings, it is recommended that future researchers on the same issue or some related topics in the context of Burkina Faso or in the context of Africa should reconsider these concepts that are redefined for the need of such a particular context. Third, in regard of managerial findings, it is very important for the governmental authorities in Burkina Faso to put some measures to stop the counterfeit alcoholic beverages that is a harm to the consumers. As Jiang et al., (2018) states it, some people use alcohol to harm themselves. For example, the research reveals that alcohol consumption brings out some diseases such as liver disease, cancer, cardiovascular diseases, diabetes, high blood pressure, and kidney disease. Thus, alcohol affects some consumers' health, and some consumers also die by drinking counterfeit alcoholic beverages. Therefore, it is crucial for the political authorities and the religious authorities to involve themselves in sensitizing the consumers to moderate their alcohol consumption to avoid conflicts but also to keep their health. Political leaders and managers should take some appropriate measures to tackle the counterfeit alcohol production, for instance by increasing the control but also by requesting some quality standards and norms in term of alcohol production and sales. For further the alcohol consumption by youth is often combined with some harmful products such as strong drugs and destructive substances. The managerial findings of this research imply that the governmental authorities include alcohol education as part of the curriculum in school, to help sensitize the younger generation. It is also vital to tackle the alcohol consumption by the youth especially the teenagers with some appropriate measures to avoid some negative consequences that destroy the future generation. As in Africa management lacks innovation, it is good for managers to set some good management strategies that respond to the need of the consumers, and that create an environment where conflicts prevention mechanisms are well monitored for a peaceful and sustainable development. In regard of theoretical findings, it is necessary for researchers to take into account this research, and to recognize that alcohol consumption in the context of Burkina Faso generates some household conflicts; however, the motives for alcohol consumption are 
slightly different from other contexts. This implies that researchers consider the context of Burkina Faso as a particular context (Nasse, 2012) as this research leads to new theoretical findings that are unique to such a socio-cultural context. In terms of methodological findings, future researchers could inspire themselves about the created tools in order to measure the variables, the used research method to make their research in the particular socio- cultural context of Burkina Faso. It will also help researchers to have a very explicit, well-organized, meticulous and methodical approach that will surely bring out some appropriate quantitative results.

\section{Conflict of Interests.}

The author has not declared any conflict of interests.

\section{Acknowledgements.}

The author would like to thank the German authorities and the DAAD program (Grant Number : 17000736), the University for Development Studies, Thomas Sankara University, the Saint Thomas d'Aquin University, the New Dawn University, Ancestry Azaaban (AZ), Global Impact Services (GIS), Fukunaga Architects Engineers (FAE), Bethel Hamliri, and all the persons who have contributed to this research.

\section{References}

Alam, S.S., Mohd, R., \& Hisham, B. (2011). Is religiosity an important determinant on Muslim consumer behaviour in Malaysia? Journal of Islamic Marketing, 2(1), 83-96.

Al-Hyari, K., M., Alnsour, G., Al-Weshah, \& Haffar, M. (2012). Religious beliefs and consumer behaviour: from loyalty to boycotts. Journal of Islamic Marketing, 3(2), 155174.

Amankwaa, A. A., W., Reed, \& Owens, De' A. (2012). Church attendance and alcohol consumption level: reasons for not drinking alcohol among college students. International Journal of Humanities and Social Science, 2(4), 1-8.

Anderson, D. R., Sweeney, D. J., Williams, T. A., Camm, J. D., \& Cochran, J. J. (2015). Statistiques pour l'économie et la gestion. (5 ${ }^{\text {ème }}$ éd.). Paris, PA: Distribution Nouveaux Horizons.

Awedoba, A. K. (2011). An ethnographic study of Northern Ghanaian conflicts: towards sustainable peace. Accra, AC: Sub-Saharan Publishers.

Bazié, J. (2011). Comprendre la communication en milieu traditionnel. Ouagadougou, OU: Les Presses Africaines.

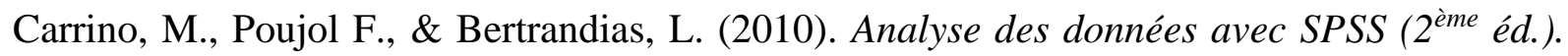
Paris, PA : Pearson éducation.

Creswell, J. W. (2009). Research design: qualitative, quantitative and mixed methods approach. California, CA: Sage Publication.

Dery, I., \& Diedong, A. L. (2014). Domestic violence against women in Ghana: an exploratory study in Upper West Region, Ghana. International Journal of Humanities and Social Science, 4(12), 228-244.

Deutsch, M. (1973). The resolution of conflicts constructive and destructive processes. New Haven, NH: Yale University Press. 
Diop, F. (2004). L'achat familial en Afrique. Dakar, DA : École Supérieure Polytechnique de Dakar, Université Cheikh Anta Diop.

Diop, F. (2012). L'influence de la religion musulmane sur le comportement de consommation au Sénégal. Dakar, DA : École Supérieure Polytechnique de Dakar, Université Cheikh Anta Diop.

Dumbili, E. (2013). Changing patterns of alcohol consumption in Nigeria: an exploration of responsible factors and consequences. A Journal of the BSA MedSoc Group 7(1):20-33.

Fam, K. S., Waller, D. S., \& Erdogan, B. Z. (2002). The influence of religion on attitudes towards the advertising of controversial products. European Journal of Marketing, 38(5/6), 537-555.

Ganassali, S. (2009). Les enquêtes par questionnaires avec sphinx. Paris, PA : Pearson Éducation.

Ger, G. (2005). Religion and consumption: the profane sacred. Advances in Consumer Research, 32(44), 79-81.

Gulliver, P. H. (1979). Disputes and negotiations: A cross-cultural perspective. New York, NY : Academic Press.

Hejase A. J. \& Hejase H. J. (2013). Research methods, a practical approach for business students ( $2^{\text {nd }}$ ed.). Philadelphia, PH : Masadir Inc.

Institut national de la statistique et de la démographie, (2010). Recensement général de la population et de l'habitat 2006, rapport définitif, Ouagadougou, Burkina Faso.

Jiang, H., Xiang, X., Hao, W., Room, R., Zhang, X., \& Wang, X. (2018). Measuring and preventing alcohol use and related harm among young people in Asian countries: a thematic review. Global Health Research and Policy, 3(14), 1-14.

Kitchathorn, P. (2009). Factor influencing customer repurchase intention: an investigation of switching barriers that influence the relationship between satisfaction and repurchase intention in the low-cost airlines industry in Thailand. Adelaide, AD: University of South Australia.

Lankoandé, I., \& Ouédraogo, A. (2016). Une mise en perspective exploratoire de la perception de la responsabilité sociétale de l'entreprise (RSE) au Burkina Faso : regards croisés sur trois (3) entreprises publiques. Journal Ouest-Africain des Sciences de Gestion, 1(1), $55-71$.

Le Petit Larousse Illustré, (2006). Langue : français. Paris, PA: Éditions Larousse.

Mahama, E. S., \& Longi, F. T. (2013). Conflicts in Northern Ghana: search for solutions, stakeholders and way forward. Ghana Journal of Development Studies, 10(1/2), 112129.

Marfo, S., \& Musah, H. (2018). Examining the position of the chieftaincy institution in modern political system of Ghana. Journal of Sociology and Social Work, 6(1), 64-72.

Marx, K. (1886). Das Kapital. New York, NY: Humboldt Publishing Co.

Murphy, C. M., Winters, J., O'Farrell, T. J., Fals-Stewart, W., \& Murphy, M. (2005). Alcohol consumption and intimate partner violence by alcoholic men: comparing violent and nonviolent conflicts. Psychology of Addictive Behaviors, 19(1), 3542. https://doi.org/10.1037/0893-164X.19.1.35

Nasse B. T. (2012). How to succeeding in Church missionarial work in West Africa. Saarbrücken, SA: Lambert Academic Publishing. 
Nasse, B. T. (2016). L'équité interne dans la gestion de la relation client : une étude comparative quantitative de trois entreprises privées du Burkina Faso. Université Aube Nouvelle, Journal Ouest-Africain des Sciences de Gestion, 1(1), 38 -54.

Nasse, B. T., Ouédraogo, A. \& Diop, F. (2016). L'influence de la religiosité sur les comportements des consommateurs à l'égard des boissons industrielles non alcoolisées : une étude quantitative et une étude qualitative portant sur les musulmans dans le contexte du Burkina Faso. Journal Ouest Africain de Sciences de Gestion, 1(2), 1-28.

Nasse, B. T. (2018). Pratiques religieuses et comportement de consommation dans un contexte africain : une étude exploratoire sur les consommateurs au Burkina Faso. Thèse de Doctorat en sciences de Gestion, spécialité marketing. Ouagadougou, OU: Université Aube Nouvelle et Université Cheikh Anta Diop.

Nasse, B. T., Ouédraogo, A. \& Diop, F. (2019). Religiosity and consumer behavior in developing countries: An exploratory study on Muslims in the context of Burkina Faso. African Journal of Business Management, 13(4), 116-127.

Nassè, T. B. (2019). Alcohol consumption and conflicts in developing countries: A qualitative and a quantitative research concerning Christian consumers in Burkina Faso. African Journal of Business Management, 13(15), 474-489.

Ouédraogo, A. (2007). Strategic management in African firms: a local perspective. Problems and Perspectives in Management, 5(1), 82-94.

Porter, C. (2013). The religion of consumption and Christian neighbor love. Chicago, $\mathrm{CH}$ : Loyola University.

Poulose, B., \& Srinivasan, K. (2009). High risk behaviours following alcohol use in alcohol dependent men. Indian journal of Medical Research, 129(1), 376-381.

Pruitt, D. G, \&. Rubin. J. Z. (1986). Social conflict: escalation, stalemate, and settlement. New York, NY: Random House.

Quivy, R., \& Van Campenhoudt, L. (2011). Manuel de recherche en sciences sociales (2 ${ }^{\text {ème }}$ éd.). Paris, PA: Dunod.

Ritchie, H., \& Roser, M. (2020). Alcohol consumption. Published online at OurWorldInData.org. Retrieved from: 'https://ourworldindata.org/alcoholconsumption' [Online Resource]

Ross, M. H. (1993). The management of conflict: interpretations and interests in comparative perspective. London, LO: Yale University Press.

Sabogu, A., Nassè, T. B., Osumanu, I. K. (2020). Understanding land conflicts and food security in West Africa: triggers and perspectives from Dorimon in Ghana. International Journal of Economics, Business and Management Research, 4(6), 84-108.

Sicard, D., \& Rognon, F. (2015). Vivre le conflit. Proteste 142(1), 10-17.

Shapiro, A. (1960). Social class theory, the clearing house. A Journal of Educational Strategies, Issues and Ideas, 34(9), 521-525. DOI:10.1080/00098655.1960.11475780.

Sulemana, M. (2009). Understanding the causes and impacts of conflicts in the Northern Region. Ghana Policy Journal the Institute of Economic Affairs, 3(4), 110-139.

Valentine, G., Jayne, M., Gould, M., \& Keenan, J. (2010). Family life and alcohol consumption: A study of the transmission of drinking practices. Joseph Rowntree Foundation, 1(1), 4-59. 